\title{
PRODUÇÃO DE SILAGEM DE CAPIM-MARANDU (Brachiaria brizantha Stapf cv. Marandu) COM E SEM EMURCHECIMENTO
}

\author{
Production of marandu grass \\ (Brachiaria brizantha Stapf cv. Marandu) Silage with and without wilting
}

\begin{abstract}
Antônio Ricardo Evangelista ${ }^{1}$, Joadil Gonçalves de Abreu ${ }^{2}$, Pedro Nelson Cesar do Amaral ${ }^{3}$, Rosana Cristina Pereira ${ }^{3}$, Flavio Moreno Salvador ${ }^{3}$, Ronan Aparecido Valadares Santana ${ }^{4}$
\end{abstract}

\section{RESUMO}

Este experimento foi conduzido com o objetivo de avaliar algumas características da silagem de capim-marandu ( $\mathrm{Bra}$ chiaria brizantha Stapf cv. Marandu) submetida a diferentes tempos de emurchecimento. O delineamento experimental usado foi o inteiramente casualizado com quatro tratamentos e quatro repetições. Os tratamentos foram tempos de emurchecimento de zero, duas, quatro e seis horas após o corte, em pleno sol. A gramínea foi colhida com aproximadamente 90 dias de rebrota e permaneceu ensilada por 40 dias em silos experimentais de canos de PVC. Determinaram-se os valores de pH, poder tampão (PT) e os teores de MS, PB, FDN, FDA e nitrogênio amoniacal $\left(\mathrm{N}_{-} \mathrm{NH}_{3}\right)$. Pelas características analisadas, pôde-se concluir que o capim-marandu ensilado após emurchecimento de 1,32 a 3,02 horas pode ser satisfatoriamente armazenado na forma de silagem, conciliando vantagens operacionais e de qualidade da forragem.

Termos para indexação: Emurchecimento, matéria seca, nitrogênio amoniacal, pH, proteína bruta.

\section{ABSTRACT}

The experiment was conducted with the objective to evaluate some characteristics of the silage of marandu grass (Brachiaria brizantha Stapf cv. Marandu) submitted to different wilting times. The completely randomized design with four treatments and four replicates was used. The treatments were wilting time of zero, two, four and six hours after the cut, in broad sunligth. The grass was harvested after 90 days of sprouting and stored for 40 days in experimental silos of PVC tube. $\mathrm{pH}$ values, buffer power (BC) and contents of $\mathrm{DM}, \mathrm{CP}, \mathrm{NDF}, \mathrm{ADF}$ and ammonium nitrogen $\left(\mathrm{N}_{-} \mathrm{NH}_{3}\right)$ were determined. The analyzed characteristics allowed to conclude that marandu grass stored after wilting of 1,32 at 3,02 hours, could be preserved satisfactorily in the form of silage, conciliating operationals advantages and forage quality.

Index terms: Wilting, dry matter, ammonium nitrogen, $\mathrm{pH}$, crude protein.

(Recebido para publicação em 28 de julho de 2003 e aprovado em 22 de outubro de 2003)

\section{INTRODUÇÃO}

As forrageiras tropicais apresentam elevada produção de matéria seca, com estacionalidade marcante entre as estações das "águas" e "seca". A estacionalidade determina distribuição desuniforme da produção ao longo do ano, indicando grande potencial para conservação de forragens por meio da ensilagem e/ou fenação. Entretanto, essas forrageiras apresentam baixo teor de matéria seca, alto poder-tampão e baixo teor de carboidratos solúveis nos estágios de crescimento em que apresentam bom valor nutritivo, colocando em risco o processo de conservação por meio da ensilagem, devido às possibilidades de surgirem fermentações secundárias.
A remoção parcial de água da planta, por meio do emurchecimento ou pré-secagem, pode ser uma opção interessante, por proporcionar condições ideais para o crescimento de bactérias láticas, e assim permitir que o excedente da forragem produzida nas pastagens ou em áreas de cultivo exclusivas para o corte possa ser armazenado e utilizado na alimentação dos animais durante o período de escassez (PEREIRA e REIS, 2001).

A produção de silagem pré-secada é considerada atualmente uma ferramenta indispensável para viabilizar os sistemas de produção de forragens conservadas nas condições tropicais. Como as chuvas são intensas durante o período de verão, a possibilidade de produção de silagem, além de feno, surge como uma alternativa

\footnotetext{
1. Engenheiro Agrônomo, D.Sc., Professor do Departamento de Zootecnia da Universidade Federal de Lavras/UFLA - Caixa Postal 37 - $37200-000$ - Lavras, MG, Bolsista CNPq.

2. Engenheiro Agrônomo, M.Sc., Doutorando do Departamento de Zootecnia/UFLA.

3. Zootecnista, M.Sc., Doutorando do Departamento de Zootecnia/UFLA.

4. Estudante de Graduação em Zootecnia, Departamento de Zootecnia/UFLA, Bolsista CNPq
} 
para reduzir as perdas por chuvas durante a fenação, num período em que produção de forragem é favorecida pelas condições ambientais. A produção de silagem pré-seca, associada à produção de feno, maximiza a colheita da forragem por hectare e reduz o custo fixo do feno produzido ao longo do ano (CASTRO, 2002).

Castro (2002) verificou que a ensilagem direta da forragem de Tifton 85 (Cynodon sp.), sem emurchecimento, produziu silagem de menor qualidade, caracterizada por alto conteúdo de nitrogênio amoniacal e baixa estabilidade aeróbia. O uso do emurchecimento a conteúdos de MS superiores a $550 \mathrm{~g} / \mathrm{kg}$ MS levou à restrição no crescimento de microrganismos e conseqüentemente redução na fermentação. $\mathrm{O}$ uso do emurchecimento em nível médio de MS, $450 \mathrm{~g} / \mathrm{kg}$ MS favoreceu as características qualitativas de fermentação e a composição química das silagens.

Berto e Muhlbach (1997) observaram que a aveia-preta (Avena strigosa Schreb) sem emurchecimento apresentou condições desfavoráveis para ensilagem, devido ao elevado conteúdo de água no momento do corte e ao alto poder-tampão. $\mathrm{O}$ emurchecimento da aveia resultou em acentuada elevação do teor de MS (15,3 para $31,2 \%)$ e redução do poder-tampão, determinando condições de fermentação superiores às da aveia sem emurchecimento. Por outro lado, Tosi et al. (1995), trabalhando com emurchecimento do capimelefante anão (Pennisetum purpureum Schum. cv. Mott), verificaram aumento no poder tampão com o incremento do conteúdo de MS.

Em relação ao teor de carboidratos solúveis, os efeitos do emurchecimento também são conflitantes em virtude de o teor variar em função do tempo de secagem, espécie, momento do corte e idade da planta. Wilson (1948), citado por Monteiro (1999), afirmou que certas espécies de plantas, quando sofrem emurchecimento, podem conter quase duas vezes a quantidade de CHOs na matéria original. Por outro lado, o aumento excessivo do teor de MS pode provocar redução na fermentação pela diminuição da concentração de CHOs em água, causada pelo emurchecimento prolongado.

A presença de amônia na silagem é fator constantemente medido para se avaliar sua qualidade, indicando valores de $8 \%$ do $\mathrm{N}$-Total como níveis criteriosos para silagens bem fermentadas. A extensão da proteólise tende a decrescer com o aumento do teor de MS do material a ser ensilado, embora alguns resultados na literatura não indiquem claramente esse fato, havendo necessidade de serem verificados outros aspectos, como a velocidade de queda do $\mathrm{pH}$, o teor de $\mathrm{PB}$ da planta e a temperatura do silo (PITT et al., 1985).

O tempo de secagem do material no campo é dependente das condições climáticas da região, principalmente intensidade de radiação solar, velocidade do vento, umidade relativa do ar e temperatura. Em trabalho efetuado em Cuba com Cynodon dactylon cv. Coast-cross, Rodriguez et al. (1989) mostraram que a présecagem por sete horas promoveu melhoria no padrão de fermentação em relação ao material fresco e concluíram que o mínimo de $35 \%$ MS deve ser indicado para ensilagem do Coast-cross. Entretanto, Pitt et al. (1985) ressaltaram a importância de não desidratar excessivamente o material a ser ensilado, alertando para a possibilidade de perdas no campo ao redor de $10 \%$, e enfatizaram o surgimento de nutrientes indigestíveis, como o NIDA (Nitrogênio Insolúvel em Detergente Ácido) no processo da ensilagem, devido ao aquecimento do material no silo (reação de "Maillard"). Os mesmos autores alertaram que poderão haver perdas iniciais devido à má compactação, atrasando o início da fase anaeróbia.

Evangelista et al. (2000), avaliando os efeitos do emurchecimento sobre a composição bromatológica da silagem de estrela roxa (Cynodon nlemfluensis Vanderyst), observaram elevação do $\mathrm{pH}$ e dos conteúdos de cinza, cálcio e fósforo e redução no teor de fibra em detergente neutro (FDN) com o aumento do conteúdo de MS da forragem. Os teores de PB, fibra em detergente ácido (FDA) e energia bruta (EB) não foram alterados pelo emurchecimento.

Monteiro (1999) concluiu que, comparado ao feno, a silagem pré-secada permite redução do tempo de secagem e dos riscos de perdas no campo. As forrageiras mais utilizadas para a produção de silagem présecada são azevém, triticale, aveia, centeio, cevada, alfafa, Tifton 85 e Coast-cross. No Brasil, a técnica do emurchecimento tem sido preferencialmente usada em regiões de elevada produção de leite, sendo considerada como um dos sistemas mais modernos de produção de volumosos, devido ao menor risco de perdas em comparação com a fenação. Atualmente, as regiões de Castro e Carambeí-PR são onde mais se ensilam forragens submetidas à pré-secagem, utilizando azevém, triticale, aveia e alfafa. Do total de matéria seca (MS) das silagens fornecidas às vacas leiteiras da região, $65 \%$ provêm da silagem pré-seca de azevém ou aveia e $35 \%$ é proveniente da tradicional silagem de milho. Se forem comparadas as silagens pré-secas com a de milho, verifica-se que a silagem de milho possui entre 6 a $8 \%$ de proteína bruta $(\mathrm{PB})$, enquanto a silagem pré-seca de

Ciênc. agrotec., Lavras, v. 28, n. 2, p. 443-449, mar./abr., 2004 
azevém apresenta 13 a $14 \%$ de PB, quando feita antes de as plantas florescerem.

Considerando a escassez de informações sobre a ensilagem de gramíneas do gênero Brachiaria, desenvolveu-se o presente estudo com o objetivo de avaliar algumas características da silagem de capimmarandu (Brachiaria brizantha Stapf cv. Marandu) submetida a diferentes tempos de emurchecimento.

\section{MATERIAL E MÉTODOS}

O presente trabalho foi conduzido em área pertencente ao Departamento de Zootecnia da Universidade Federal de Lavras-MG. Segundo Castro Neto et al. (1980), Lavras está situada a $21^{\circ} 14^{\prime}$ de Latitude Sul e $45^{\circ} 00^{\prime}$ de Longitude Oeste de Greenwich, com altitude média de 910 m. O clima, segundo a classificação de Koppen, é do tipo Cwb, caracterizando-se por duas estações bem definidas: seca (abril a setembro) e chuvosa (outubro a março). A precipitação anual média é de $1493 \mathrm{~mm}$ e as temperaturas médias de máxima e de mínima são de 26,0 e $14,6^{\circ} \mathrm{C}$, respectivamente.

O capim-marandu (Brachiaria brizantha Stapf cv. Marandu) foi colhido em 07/03/2003, após aproximadamente 90 dias de rebrota, sendo o corte realizado com roçadeira costal motorizada. $\mathrm{O}$ corte foi efetuado às 8 horas e 30 minutos e a gramínea permaneceu no campo espalhada uniformemente, sendo submetida a diferentes tempos de emurchecimento. Os dados meteorológicos durante a colheita, emurchecimento e ensilagem da forragem foram: precipitação pluviométrica: $0 \mathrm{~mm}$; radiação solar: 10 horas e 12 minutos; umidade relativa do ar: $74 \%$; temperatura média: $23,1^{\circ} \mathrm{C}$; temperatura máxima: $31,3^{\circ} \mathrm{C}$; temperatura mínima: $18,0^{\circ} \mathrm{C}$; velocidade média do vento: $1,50 \mathrm{~m} / \mathrm{s}$.

O delineamento experimental utilizado foi o inteiramente casualizado com quatro tratamentos e quatro repetições. Os tratamentos consistiram nos tempos de pré-emurchecimento de zero, duas, quatro e seis horas após o corte, em pleno sol. A forragem foi picada em tamanho de 1 a $2 \mathrm{~cm}$. Como silos experimentais, utilizaram-se canos de PVC com $10 \mathrm{~cm}$ de diâmetro e $50 \mathrm{~cm}$ de comprimento, com capacidade para, aproximadamente, $2,50 \mathrm{~kg}$ de silagem $\left(600 \mathrm{~kg} / \mathrm{m}^{3}\right)$. A compactação foi realizada com pêndulos de ferro e o fechamento com tampas de PVC, dotadas de válvula tipo Bunsen, sendo as tampas lacradas com fita adesiva.

Parte do material original picado foi amostrado no momento da ensilagem, sendo essa amostra colocada em sacos de papel e secas em estufa de ventilação forçada com temperatura de $60-65^{\circ} \mathrm{C}$ por 72 horas. As amostras pré-secas foram pesadas e moídas utilizando moinho estacionário com peneira de $1 \mathrm{~mm}$, e guardadas em recipientes de polietileno para análise do teor de MS antes de ensilar, conforme metodologia da AOAC (1975). A outra parte do material original picado foi congelada em sacos plásticos para análise do poder-tampão (PT), pelo método de Playne e McDonald (1966).

A abertura dos silos ocorreu aos 40 dias após a ensilagem. Na coleta das amostras, foram desprezados os $5 \mathrm{~cm}$ da porção superior e inferior dos silos. Após esse procedimento, a silagem foi homogeneizada e dividida em duas partes. A primeira parte foi acondicionada em sacos plásticos e congelada para análise do nitrogênio amoniacal $\left(\mathrm{N}-\mathrm{NH}_{3}\right)$, segundo método descrito por Tosi (1973). A outra parte, aproximadamente $800 \mathrm{~g}$, foi colocada em sacos de papel e secas em estufa de ventilação forçada com temperatura de $60-65^{\circ} \mathrm{C}$ por 72 horas. As amostras pré-secas foram pesadas e moídas utilizando moinho estacionário com peneira de malha de $1 \mathrm{~mm}$, e guardadas em recipientes de polietileno para análises posteriores. A avaliação do $\mathrm{pH}$ também foi realizada por ocasião da abertura dos silos experimentais, utilizando-se $9 \mathrm{~g}$ da amostra em $60 \mathrm{~mL}$ de água destilada.

Os teores de matéria seca (MS) e de proteína bruta (PB) foram determinados conforme métodos recomendados pela AOAC (1975). Os teores de fibra em detergente neutro (FDN) e fibra em detergente ácido (FDA) foram determinados segundo as técnicas descritas por Goering e Soest (1970). Os dados coletados foram submetidos à análise de variância e regressão, conforme metodologia descrita por Banzato e Kronka (1992), utilizando-se o software SAEG.

\section{RESULTADOS E DISCUSSÃO}

Houve resposta linear em função do aumento do tempo de emurchecimento para as variáveis teor de MS antes de ensilar (MSA), teor de MS da silagem (MSS), poder-tampão e $\mathrm{pH}$ da silagem de capim-marandu (Quadro 1).

Com relação ao teor MSA, observou acréscimo de 5,88 unidades percentuais para aumento de cada hora de secagem. Dessa forma, observou-se que com seis horas de secagem em pleno sol, o teor de MS elevou-se de 27,22 para 62,50\%, considerando as condições climáticas no dia: temperatura média, $23,1^{\circ} \mathrm{C}$; umidade relativa do ar, $74 \%$; precipitação, $0 \mathrm{~mm}$; 
radiação solar, dez horas e 12 minutos. É importante destacar que não houve revolvimento da massa de forragem durante a secagem.

Por outro lado, Vilela (1998) verificou que os resultados experimentais decorrentes da prática do emurchecimento após o corte manual do capim-elefante têm sido contraditórios. Quando o capim-elefante é submetido ao emurchecimento de quatro a seis horas, o teor de MS não se eleva além de 3 a 8 unidades percentuais. Esses pequenos aumentos de MS decorrem da resistência física que a parede celular da planta exerce sobre a perda de água, fazendo com que essa prática nem sempre seja tão eficiente para o capim-elefante.

Monteiro (1999) destacou que o emurchecimento permitiu a produção de silagens de boa qualidade a partir de forrageiras que apresentavam como limitação principal o reduzido teor de MS no momento do corte, como no caso das gramíneas e, somado a isso, o elevado poder-tampão, no caso das leguminosas. Segundo Woolford (1984), a atividade clostridiana na silagem com teor de MS entre 35 a $40 \%$ é substancialmente reduzida ou inexistente, permitindo que as bactérias ácido láticas produzam ácido lático suficiente para estabilizar a silagem. O ideal para ensilagem é que a forragem apresente teores de MS entre 35 e 45\%, e para os teores entre 40 a $45 \%$, é recomendável que a forragem seja picada em partículas menores, a fim de se conseguir melhor compactação (PEREIRA e REIS, 2001). Nas condições do experimento com capim-marandu, foi necessário emurchecimento entre 1,32 a 3,02 horas, para que a MS da forragem atingisse o ideal (35 a 45\%).

Considerando que é comum na época ideal de corte das forrageiras um dia ou apenas algumas horas de sol aberto, seguido de dias chuvosos consecutivos, essa característica de rápida perda de umidade se traduz em substancial vantagem do capim-marandu em rela- ção a outras espécies forrageiras. Berto e Muhlbach (1997), trabalhando com aveia-preta colhida aos 66 dias após o plantio, necessitaram de 26 horas de exposição da forragem ao sol para elevar o teor de MS da silagem de 15,3 para $31,2 \%$.

Vilela (1998) mencionou que o limite superior de $\mathrm{pH}$ para as silagens de qualidade satisfatória é de 4,2 . Com o capim-marandu, as silagens que foram submetidas ao emurchecimento por seis horas apresentaram valores de $\mathrm{pH}(4,15)$ próximos ao limite máximo. Entretanto, esses valores de $\mathrm{pH}$ foram bem inferiores aos obtidos por Pitt et al. (1985) em alfafa com $73 \%$ MS, cujo valor de $\mathrm{pH}$ chegou a atingir 6,00. O emurchecimento determina menor intensidade do processo de fermentação, traduzido pelo maior $\mathrm{pH}$ com o incremento do conteúdo de MS da forragem ensilada, corroborando com a literatura (UMANA et al., 1991; TOSI et al., 1995; WYSS, 1999; EVANGELISTA et al., 2000).

Com relação ao PT, verificou-se diminuição de aproximadamente 1,59 eq.mg HCL/100g MS para acréscimo de hora de secagem. Berto e Muhlbach (1997) encontraram redução de $14,6 \%$ do PT quando a aveia-preta foi submetida ao emurchecimento. Evangelista et al. (2002), avaliando a pré-secagem da aveia durante zero, quatro, cinco e seis horas em pleno sol, encontraram valores de poder tampão de 14,$03 ; 7,38 ; 7,28$ e 5,87 eq.mg HCL/100g MS, respectivamente.

Não houve diferença significativa nos teores de fibra em detergente neutro (FDN) e fibra em detergente ácido (FDA) das silagens de capim-marandu em função dos diferentes tempos de emurchecimento (Quadro 2). Os teores de FDN variaram entre 67,65 a 69,39\%; ao passo que os teores de FDA oscilaram entre 43,65 a $45,14 \%$.

QUADRO 1 - Efeito do emurchecimento no teor de matéria seca antes de ensilar (MSA), teor de matéria seca da silagem (MSS), poder-tampão (PT) e pH da silagem de capim-marandu (Brachiaria brizantha Stapf cv. Marandu).

\begin{tabular}{|c|c|c|}
\hline Características avaliadas & Equações & $\mathbf{R}^{2}$ \\
\hline MAS (\%) & $\mathrm{Y}=27,2213+5,87940 \mathrm{x}$ & 0,9276 \\
MSS (\%) & $\mathrm{Y}=25,8540+5,67612 \mathrm{x}$ & 0,9452 \\
PT (eq.mg HCl/100 g MS) & $\mathrm{Y}=21,3300-1,58915 \mathrm{x}$ & 0,8810 \\
$\mathrm{pH}$ & $\mathrm{Y}=3,5675+0,0975 \mathrm{x}$ & 0,7339 \\
\hline
\end{tabular}

Ciênc. agrotec., Lavras, v. 28, n. 2, p. 443-449, mar./abr., 2004 
QUADRO 2 - Efeito do emurchecimento no teor de fibra em detergente neutro (FDN) e fibra em detergente ácido (FDA) da silagem de capim-marandu (Brachiaria brizantha Stapf cv. Marandu).

\begin{tabular}{|c|c|c|}
\hline $\begin{array}{c}\text { Tempo de emurchecimento } \\
\text { (horas) }\end{array}$ & $\begin{array}{c}\text { FDN } \\
(\% \text { MS) }\end{array}$ & $\begin{array}{c}\text { FDA } \\
(\% \text { MS) }\end{array}$ \\
\hline 0 & 67,65 & 43,84 \\
2 & 69,39 & 45,14 \\
4 & 68,31 & 44,83 \\
6 & 68,17 & 43,65 \\
\hline
\end{tabular}

Resultados semelhantes foram encontrados por Rangrab et al. (1997), citados por Monteiro (1999), comparando as características químico-bromatológicas da silagem de aveia-preta sem e com emurchecimento, os quais não observaram diferenças significativas nos teores de FDN (46,7 e 47,5\% MS) e FDA (34,8 e $32,4 \%$ MS). Williams et al. (1995), avaliando a silagem de trigo com e sem emurchecimento, também não encontraram diferenças quanto ao teor de FDN (58\% MS) e FDA (33\% MS). Por outro lado, Evangelista et al. (2000) verificaram redução no FDN com o aumento no conteúdo de MS da forragem ensilada de estrela-roxa. No entanto, não observaram variação nos teores de FDA das silagens devido ao emurchecimento.

Não houve diferença significativa nos teores de proteína bruta $(\mathrm{PB})$ e nitrogênio amoniacal $\left(\mathrm{N}-\mathrm{NH}_{3}\right)$ das silagens de capim-marandu em função dos diferentes tempos de emurchecimento (Quadro 3).

QUADRO 3 - Efeito do emurchecimento no teor de proteína bruta $(\mathrm{PB})$ e nitrogênio amoniacal $\left(\mathrm{N}-\mathrm{NH}_{3}\right)$ da silagem de capim-marandu (Brachiaria brizantha Stapf cv. Marandu).

\begin{tabular}{|c|c|c|}
\hline $\begin{array}{c}\text { Tempo de emurchecimento } \\
\text { (horas) }\end{array}$ & $\begin{array}{c}\text { PB } \\
(\% \text { MS) }\end{array}$ & $\begin{array}{c}\text { N-NH } \\
\text { (\% N-Total) }\end{array}$ \\
\hline 0 & 5,70 & 1,96 \\
2 & 5,69 & 2,33 \\
4 & 5,26 & 2,72 \\
6 & 5,21 & 2,33 \\
\hline
\end{tabular}

Os teores de $\mathrm{PB}$ variaram entre 5,21 a 5,70\%. Quando o emurchecimento é realizado sob condições climáticas adequadas, a fermentação é restrita, resultando numa silagem com maiores valores de $\mathrm{pH}$ e o nitrogênio protéico tende a ser preservado com o aumento no teor de MS (MCDONALD et al., 1991). Evangelista et al. (2000) não observaram efeito do emurchecimento sobre o conteúdo de PB da silagem de estrela-roxa. Esses mesmos autores também não observaram efeito do pré-emurchecimento sobre o conteúdo de PB da silagem de aveia. Tosi et al. (1995) observaram efeitos positivos do emurchecimento sobre a silagem da capimelefante anão, promovendo manutenção da PB e redução de nitrogênio amoniacal em função da présecagem.

Por outro lado, Berto e Muhlbach (1997) observaram efeito positivo do emurchecimento sobre o teor de $\mathrm{PB}$ na silagem de aveia preta. Da mesma forma, o conteúdo de PB da silagem de Tifton- 85 foi influenciado pelo emurchecimento, havendo incremento nesse parâmetro com o aumento do conteúdo de MS da silagem, e tal comportamento provavelmente está associado à redução na concentração de $\mathrm{CHOs}$ durante o emurchecimento, proporcionando aumento no teor de PB (CASTRO, 2002).

Os teores de $\mathrm{N}^{-\mathrm{NH}_{3}}$ oscilaram entre 1,96 a 2,72\% do N-Total (Quadro 3). Esses teores são baixos, indicando que houve reduzida degradação da proteína bruta. Conforme Silveira (1975), as silagens que apresentam valores de $\mathrm{N}-\mathrm{NH}_{3}$ até $8 \%$ do $\mathrm{N}$-Total são consideradas de ótima qualidade.

É importante destacar que se a secagem for rápida, o conteúdo de nitrogênio amoniacal $\left(\mathrm{N}-\mathrm{NH}_{3}\right)$ não sofre alteração (MCDONALD et al., 1991). Evangelista et al. (2000) não observaram efeito do emurchecimento sobre o conteúdo de $\mathrm{N}-\mathrm{NH}_{3}$ da silagem de aveia, cujos valores foram de 3,65; 3,84 e 3,68 \% N-Total para as pré-secagens de quatro, cinco e seis horas, respectivamente. Os mesmos autores relataram conteúdo de $\mathrm{N}-\mathrm{NH}_{3}$ de 2,30\% do N-Total para a aveia sem emurchecimento.

Entretanto, Berto e Muhlbach (1997) observaram redução significativa no conteúdo de nitrogênio amoniacal com o emurchecimento da aveia-preta, em comparação ao material ensilado com umidade original (11,8 e $8,4 \%$ do N-Total, respectivamente). Wyss (1999) aplicou o processo de emurchecimento visando a atingir níveis crescentes de MS na ensilagem de gramíneas de clima temperado $(25,35,45,55$ e $65 \% \mathrm{MS})$, concluindo que o aumento do conteúdo de MS da forra- 
gem reduziu a intensidade de fermentação, traduzindo em diminuição nos teores de nitrogênio amoniacal e de ácidos orgânicos, enquanto o teor de açúcares residuais e o pH foram elevados. Umana et al. (1991) concluíram que o emurchecimento da forragem de Tifton-81 melhorou o valor nutritivo da silagem, traduzido por maiores concentrações de ácido lático, menores conteúdos de ácido acético e nitrogênio amoniacal.

\section{CONCLUSÃO}

O capim-marandu (Brachiaria brizantha Stapf cv. Marandu), com 90 dias de idade, pode ser satisfatoriamente armazenado na forma de silagem, quando submetido ao emurchecimento por 1,32 a 3,02 horas, conciliando vantagens operacionais e de qualidade da silagem.

\section{REFERÊNCIAS BIBLIOGRÁFICAS}

ASSOCIATION OF OFFICIAL AGRICULTURAL CHEMISTS. Official methods of analysis of the Association of Official Analytical Chemists. Washington, 1975. $1015 \mathrm{p}$.

BANZATO, D. A.; KRONKA, S. Experimentação agrícola. Jaboticabal: FUNEP, 1992. 247 p.

BERTO, J. L.; MUHLBACH, P. R. F. Silagem de aveia preta no estádio vegetativo, submetida à ação de inoculantes e ao efeito do emurchecimento. Revista Brasileira de Zootecnia, Viçosa, v. 26, n. 4, p. 651-658, 1997.

CASTRO, F. G. F. Uso do pré-emurchecimento, inoculante bacteriano-enzimático ou ácido propiônico na produção de silagem de Tifton 85 (Cynodon sp.). 2002. $136 \mathrm{f}$. Tese (Doutorado em Agronomia) - Escola Superior de Agricultura Luiz de Queiroz, Piracicaba, 2002.

CASTRO NETO, P.; SEDYIMA, G. C.; VILELA, E. A. Probabilidade de ocorrência de períodos secos em Lavras, Minas Gerais. Ciência e Prática, Lavras, v. 4, n. 1, p. 46-55, 1980.

EVANGELISTA, A. R.; LIMA, J. A. de; ABREU, J. G. de; SIQUEIRA, G. R.; SANTANA, R. A. V. Silagem de aveia (Avena sativa strigosa Schreb) pré-secada ou enriquecida com farelo de trigo. In: REUNIÃO ANUAL DA SOCIEDADE BRASILEIRA DE ZOOTECNIA, 39., 2002, Recife. Anais... Recife: SBZ, 2002. CD-ROM.
EVANGELISTA, A. R.; LIMA, J. A. de; BERNARDES, T. F. Avaliação de algumas características da silagem de gramínea estrela roxa (Cynodon nlemfluensis Vanderlyst). Revista Brasileira de Zootecnia, Viçosa, v. 29, n. 4, p. 941-946, 2000.

GOERING, H. K.; SOEST, P. J. van. Forage fiber analysis: apparatus, reagents, procedures and some applications. Washington: ARS, 1970. (Agricultural Handbook, 379).

McDONALD, P.; HENDERSON, A. R.; HERON, S. J. E. Biochemistry of silage. Marlow: Chalcombe, 1991. 340 p.

MONTEIRO, A. L. G. Silagem pré-secada. In: PEIXOTO, A. M.; MOURA, J. C. de; NUSSIO, L. G.; FARIA, V. P. de. Alimentação suplementar. Piracicaba: FEALQ, 1999. p. 97-122.

PEREIRA, J. R. A.; REIS, R. A. Produção e utilização de forragem pré-secada. In: SIMPÓSIO DE FORRAGICULTURA E PASTAGENS. TEMAS EM EVIDÊNCIA, 2., 2001, Lavras. Anais... Lavras: UFLA, 2001. p. 235-254.

PITT, R. E.; MUCK, R. E.; LEIBENSPERGER, R. Y. A quantitative model of the ensilage process in lactates silages. Grass and Forage Science, Oxford, v. 40, n. 3, p. 279-303, 1985.

PLAYNE, M. J.; McDONALD, P. The buffering constituents of herbage and of silage. Journal of the Science of Food and Agricultural, London, v. 17, p. 262-268, 1966.

RODRIGUEZ, J. A.; POPPE, S.; MEIER, H. The influence of wilting on the quality of tropical grass silage in Cuba. 4: bermuda grass cv. Coast-cross (Cynodon dactylon). Archives of Animal Nutrition, Rostock, v. 39, n.10, p. 851-857, 1989.

SILVEIRA, A. C. Técnicas de produção de silagem. In: SIMPÓSIO SOBRE MANEJO DA PASTAGEM, 2., 1975, Piracicaba. Anais... Piracicaba: FEALQ, 1975. p. 156-180.

TOSI, H. Ensilagem de gramíneas tropicais sob diferentes tratamentos. 1973. $107 \mathrm{f}$. Tese (Doutorado em Produção Animal) - Universidade Estadual Júlio Mesquita Filho, Botucatu, 1973. 
TOSI, H.; RODRIGUES, L. R. A.; JOBIM, C. C.; OLIVEIRA, M. S.; SAMPAIO, A. A. M.; ROSA, B. Ensilagem do capim elefante cv. Mott sob diferentes tratamentos. Revista Brasileira de Zootecnia, Viçosa, v. 24, n. 6, p. 909-916, 1995.

UMANA, R.; STAPLES, C. R.; BATES, D. B. Effects of the digestibility of bermudagrass ensiled at two moisture contents. Journal of Animal Science, Albany, v. 69, n. 11, p. 4588-4601, 1991.

VILELA, D. Aditivos para silagem de plantas de clima tropical. In: SIMPÓSIO SOBRE ADITIVOS NA PRODUÇÃO DE RUMINANTES E NÃO RUMINANTES, 1998, Botucatu. Anais... Botucatu: SBZ, 1998. p. 73-108.
WILLIAMS, C. G.; FROETSCHEL, M. A.; ELY, L. O.; AMOS, H. E. Effects of inoculation and wilting on the preservation and utilization of wheat forage. Journal of Dairy Science, Champaign, v. 78, n. 8, p. 1755-1765, 1995.

WOOLFORD, M. K. The silage fermentation. New York: Marcel Dekker, 1984. 305 p.

WYSS, U. Influence pre-wilting degree on aerobic stability of grass silages. In: INTERNATIONAL SILAGE CONFERENCE, 7., 1998, Uppsala. Proceedings... Uppsala: Swedish University of Agricultural Science, 1999. p. 284285. 